\title{
REVIEW
}

\section{Innovating affordable neonatal care equipment for use at scale}

\author{
V Sashi Kumar ${ }^{1}$, VK Paul ${ }^{2}$ and K Sathasivam ${ }^{3}$
}

The care of small and sick neonates requires biomedical technologies, such as devices that can keep babies warm (radiant warmers and incubators), resuscitate (self-inflating bags), track growth (weighing scales), treat jaundice (phototherapy units) and provide oxygen or respiratory support (hoods, continuous positive airway pressure (CPAP) devices and ventilators). Until the 1990s, most of these products were procured through import at a high cost and with little maintenance support. Emerging demand and an informal collaboration of neonatologists, engineers and entrepreneurs has led to the production of good quality equipment of several high-volume categories at affordable cost in India. Radiant warmers, resuscitation bags, phototherapy units, weighing scales and other devices manufactured by Indian small-scale companies have enabled an expansion of neonatal care in the country, particularly in district hospitals, medical college hospitals and subdistrict facilities in the public sector as a part of the National Rural Health Mission. Indian products have acquired international quality standards and are even exported to developed nations. This paper captures this story of innovation and entrepreneurship in neonatal care.

Journal of Perinatology (2016) 36, S32-S36; doi:10.1038/jp.2016.188

\section{BACKGROUND}

At independence, in 1947, India's economy was primarily based on agriculture. The only significant industrial activity was in the textiles sector. This was despite the fact that the country was ready for industrial development: it had been generating electricity for two to three decades then, and railways had been around in India for almost a century.

The political leaders of the newly independent country had a vision of transforming India into an industrially developed nation in a planned and phased manner. Thus the thrust of the first several 5-year plans was on developing infrastructure and heavy industries, such as roads, electricity generation, steel manufacturing, manufacturing of industrial machinery and so forth.

This phase of tightly controlled growth lasted well into the 1980s. Private enterprise in India operated in an environment governed by import barriers. International products were not easily available in the country during this phase. With indigenous developments of manufactured goods being slow, the only feasible means by which international products - both industrial machines and consumer goods-could be made available in India was through partnerships between Indian companies and foreign manufacturers. Many such partnerships were, therefore, formed during this phase. The foreign participants brought in expertise and authorized their Indian partners to manufacture their products in India. The government set quotas and issued licenses that determined what a manufacturer could produce.

During this 'license raj', which lasted till the early 1990s, medical care products remained largely ignored by the Indian entrepreneurs and the government. This was despite the recognition of the need to improve life expectancy and reduce infant mortality and improve other indicators.

During this phase, the Indian industry did not focus on the medical sector. Foreign products were also not available for import under the open general license. If any equipment was procured from overseas by a hospital, it was done so at a prohibitive cost, a large part of which was the customs duty. Further, the paperwork involved was cumbersome. When the equipment needed repairs, spares had to be obtained from abroad as well-and again, the prices were high and the procedure involved was intimidating. With the number of installations being very small, service support for the equipment was feeble. As a result, the foreign medical equipment in Indian hospitals often did not work-and the standard of care of newborn infants continued to be poor.

Neonatal care becomes a priority

The National Neonatology Forum (NNF) formulated the first set of recommendations on neonatal care in India. The NNF was instrumental in placing newborn care very high among the national health priorities. This it did through sustained advocacy, academic contributions and consensus building in key program areas.

In the subsequent years, the state of affairs changed and neonatal care in India received a great boost. In 1992, well before neonatal health appeared on the international health agenda, India took the lead in incorporating essential newborn care into the national program. As a result, neonatal survival has improved greatly in India.

Behind this success lies a hitherto untold story-a story in which Indian technocrats and small-scale entrepreneurs played a crucial role.

\section{Untold success story}

In the early 1990s, India's economy was at the brink of a major change, with globalization efforts having just begun. To anyone giving the matter a thought at that time, it would have appeared obvious that it was only a question of time before international medical equipment became available in India. It would have also been evident that the service issues too would disappear as the customer bases of the international suppliers grew in India. Over

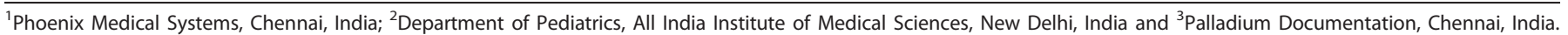
Correspondence: Dr V Sashi Kumar, Phoenix Medical Systems, 32/4, Jawaharlal Nehru Salai, Ekkattuthangal, Chennai 600032, Tamil Nadu, India.

E-mail: sashi@pmsind.com 


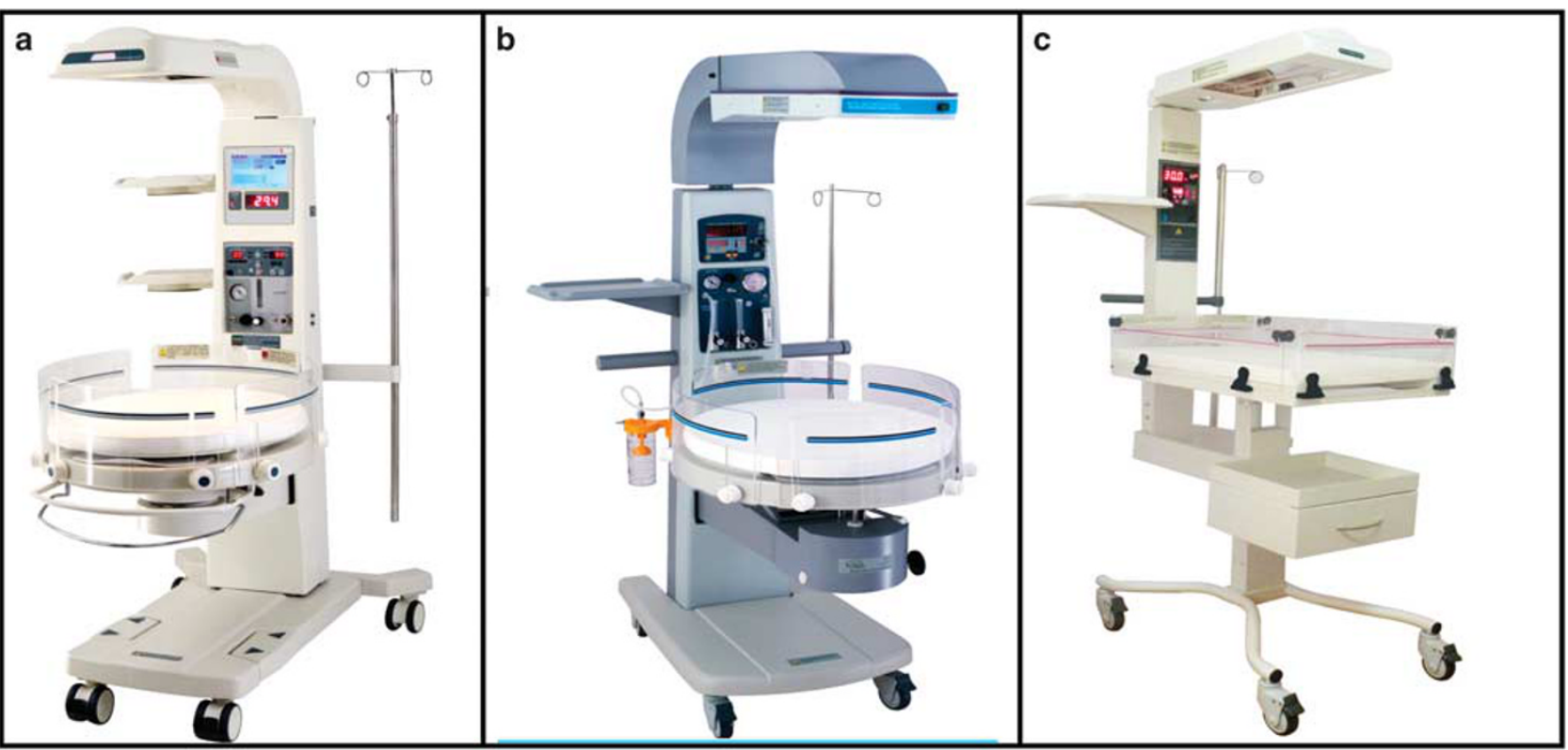

Figure 1. Indian-made radiant warmers. (a) CIC 101, (b) NRC 100 and (c) NWS 102, Phoenix Medical Systems, Chennai, India.

the next couple of decades, Indian business did grow accustomed to importing foreign products and reselling them in the Indian market. Import restrictions were indeed reduced a number of times in the new millennium, and so the customs duties became much less prohibitive.

As a result of the changes in her economic environment, India could have simply become a part of the global market for biomedical equipment. With reduced customs duties, neonatal care products manufactured by international companies would have been more affordable and would have been installed in Indian hospitals, improving the health and survival of neonates.

However, by the time the economic changes took place, a different kind of barrier had come up in India, preventing multinational companies from marketing their goods easily in the country. Over a period of 20 years or so, the Indian medical equipment industry developed rapidly and established itself sufficiently well to offer them competition. The prices of the Indian products were much lower than what the international companies could offer. At the same time, these products were of good quality. As a result, they were being installed increasingly in hospitals across the country, improving the quality of neonatal care offered at these hospitals. The outcome was that neonatal health and survival improved significantly.

The vigorous growth of the indigenous industry resulted from a number of chance collaborations between physicians and young entrepreneurs. The physicians were looking beyond day-to-day treatment of patients, and the industrialists were technically qualified entrepreneurs.

One of the seminal events that led to this highly effective physician-engineer-industry collaboration took place in 1990. A conference on biomedical equipment in neonatal care was held at the All India Institute of Medical Sciences (AlIMS), New Delhi, under the aegis of the NNF. At this event, the stakeholders took stock of the needs, challenges and regulatory constraints in relation to neonatal equipment access, quality, maintenance and affordability. ${ }^{1}$ The academic leadership of neonatology called upon Indian industry to develop affordable equipment of good quality for neonatal care. The key equipment required was specifically identified.

This event set off a spark in the Indian biomedical enterprise. Young industrialists began to work with physicians on indigenous solutions to the health problems faced by newborns, children and mothers. With the typical problem-solving approach of engineers, they sought to address the major health technology gaps. The small-scale industry developed products that were urgently required to provide neonatal infant care-incubators, infant warmers, phototherapy units and resuscitation bags.

No fewer than four companies developed infant warmers after the message at the AlIMS conference (Figure 1). These products were far more affordable than the imported alternatives-they were cheaper by even a factor of 10 !

Birth asphyxia was another major problem highlighted the AllMS meeting. From 1990, the NNF steered the Neonatal Resuscitation Program as perhaps the most comprehensive Neonatal Resuscitation Program in the developing world. Pediatricians, gynecologists and nursing staff, even dais, were trained in neonatal resuscitation. This raised awareness about quality resuscitation bags. Resuscitation bags are simple respiratory devices, but they can save a number of lives. At this point in time, the resuscitation bags that were made in India could not be sterilized optimally. These resuscitation bags also lacked pop-off valves that would limit the pressure delivered to an infant.

More than one Indian company responded to these pointers by developing better resuscitation bags locally (Figure 2). They used sterile silicone material and fitted the bags with pop-off valves that ensured that the air pressure never exceeded $40 \mathrm{~cm}$ of water column. Again, the cost of the Indian resuscitation bags was very attractive compared with the imported products.

The phototherapy units in use in the country until the late 1990s were the bulky units using long fluorescent lamps. The more sleek compact fluorescent light (CFL)-based phototherapy units that had made entry in the Western markets were not manufactured in the country (Figure 3). A Chennai-based company produced a unit with CFLs within a year of starting the effort. Needless to say, the cost of the Indian product was far lower than that of the foreign equivalent. Very soon, several other companies began to make similar CFL phototherapy units, thousands of which are now installed in the Indian nurseries. These products also found acceptance in several other countries.

Indeed, all the new products came to be widely used in all the major hospitals-significantly, they began to reach village-level hospitals and primary health centers. The NNF had a significant role in this deployment. They created awareness about the new 
equipment and provided hands-on training all over the country, including first referral units (taluk hospitals) and the primary health centers.

The NNF was also involved in various efforts aimed at strengthening the education and training of physicians and nurses in neonatal care, convinced that such education and training were important perquisites for achieving the national child health goals. The NNF provided various teaching aids on a number of topics, such as hypothermia and neonatal jaundice on its website, which included instructions on the use of relevant equipment.

Thanks to rising demand, Indian medical equipment companies grew strongly. However, the development of the industry was not without hitches. Initially the indigenous products did not meet quality standards set for imported products, and there were a number of fly-by-night operators among the new entrepreneurs. But the situation improved steadily.

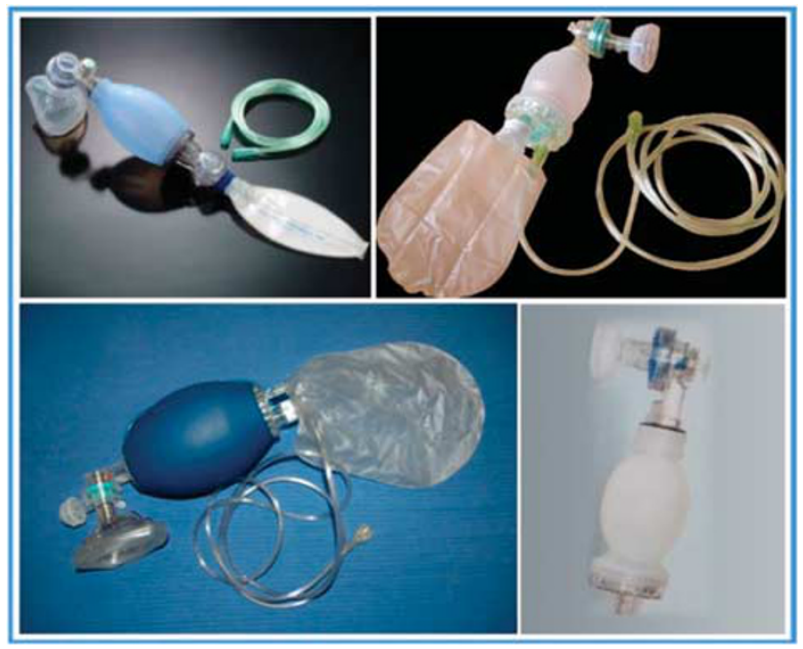

Figure 2. Made-in-India neonatal resuscitation bags. Resuscitation bag and mask, AM-100, Phoenix Medical Systems, Chennai, India.
Only the companies that set themselves high standards survived in the market. There was an absence of Indian standards for medical equipment, and the entrepreneurs adopted international (Western) standards. Many of them obtained the Conformité Européene marking and Food and Drugs Administration approval (Table 1).

In recent years, advanced neonatal intensive care units have been established in teaching and non-teaching hospitals in large cities, whereas smaller cities and towns have witnessed a dramatic growth in the number of nurseries for newborns in small private hospitals and nursing homes. In the public sector, the delivery points at subcenters, primary health centers, community health centers and district hospitals have been equipped with resuscitation equipment, including made-in-India self-inflating bags, warmers and suction units. The government has established over 450 special newborn care units (SNCUs) in district hospitals. An SNCU was envisaged as providing Level II care with a range of equipment. The equipment installed at these facilities has all been made and procured in India. More than 15000 infant warmers and 10000 phototherapy units were supplied by Indian manufacturers for use in public facilities. Indian neonatal equipment is also in place in thousands of newborn care centers at delivery points across the length and breadth of the country. In sum, neonatal care in India is backed by Indian industry.

More recently AlIMS has placed on its website high-quality webinars on neonatal equipment (www.newbornwhocc.org). A

Table 1. Conformance of Indian neonatal care equipment with international standards in 2013

\begin{tabular}{lcc}
\hline Equipment & CE marking & FDA approval \\
\hline Phototherapy & Yes & Yes \\
Warmers & Yes & Yes \\
CPAP & No & No \\
Incubators & No & No \\
\hline
\end{tabular}

Abbreviations: CE, Conformité Européene; CPAP, continuous positive airway pressure; FDA, Food and Drugs Administration.

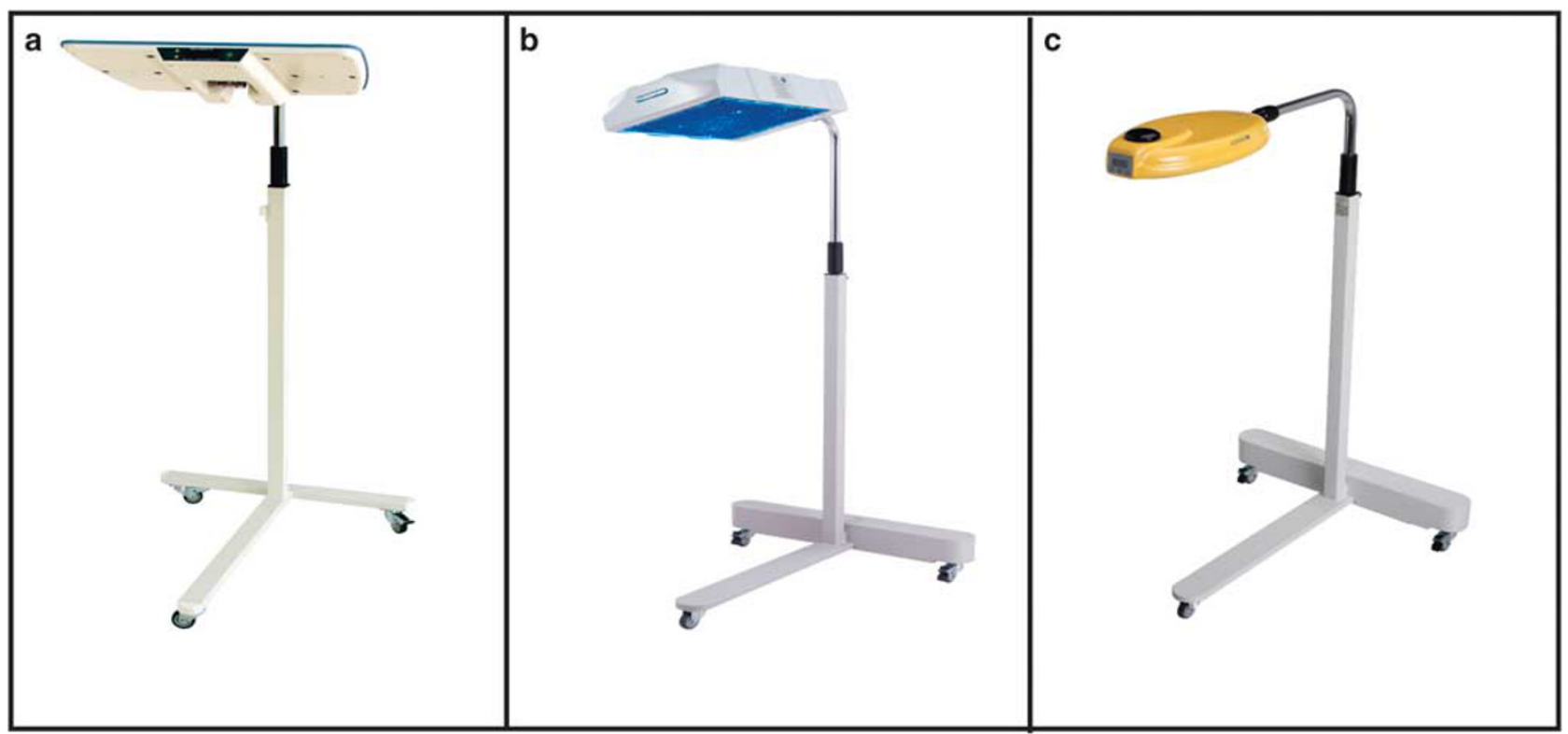

Figure 3. Made-in-India phototherapy units. (a) Brilliance Pro, (b) CFL-100 and (c) LEDPT, Phoenix Medical Systems, Chennai, India. 


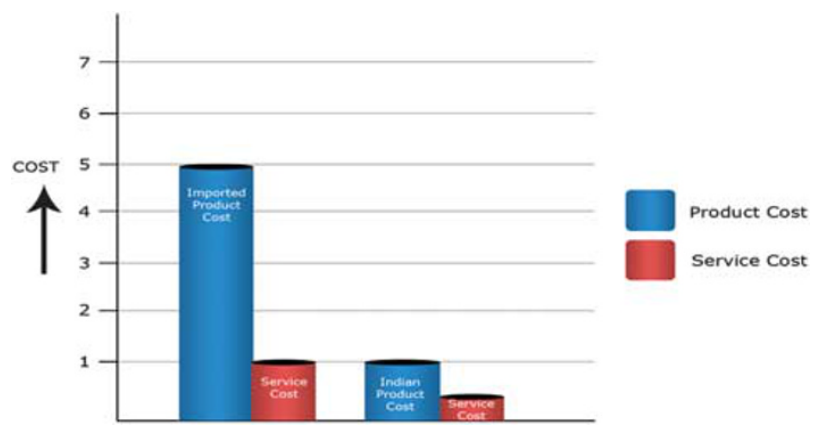

Figure 4. Illustration comparing typical costs of neonatal care equipment manufactured in India and international products.

book on neonatal equipment also effectively raised awareness about the technical basis, quality and functioning of the equipment. $^{2}$

\section{Cost-effective products}

A very significant fact that made this story possible is that the Indian products were highly cost-effective (Figure 4). They readily gained acceptance at hospitals all over India, not only in government-run institutions but also in private hospitals. Today, the vast majority of privately run medical establishments in India use only Indian neonatal equipment.

This cost-effectiveness of Indian products was noticed by UNICEF, which even developed an official document on sourcing of transport incubators. It highlighted the yawning gap between Indian and international prices. As in India, the low cost of Indian medical products is of great significance in other developing countries.

Even with lower mean time between failures, the service costs of international products are higher compared with Indian-made products.

At the same time, as expected after the globalization initiatives, multinational companies manufacturing neonatal care equipment entered India on their own-not through joint ventures. But to compete with the Indian manufacturers, they now had no option but to set up facilities in India; products made in the United States or in Europe simply could not compete with the Indian products on price. To manufacture in India was less expensive.

\section{Innovation}

Today, Indian companies no longer enjoy the advantage of lower manufacturing costs because the multinational suppliers have all set up production facilities in the country. The entry of the international companies was a challenge faced by the Indian industry, but it is notable that the Indian companies have a strength that allows them to face the competition successfully: their ability to innovate.

Imported products fall in the high-cost segment, and their volume of sales is correspondingly low. Indian products dominate the lower-cost section of the pyramid, with high volumes of sales (Figure 5).

The Indian products have features that are inventive and extremely friendly to both the infant and the caregiver. To give a couple of examples, one product features non-touch switches for examination lamps. These switches prevent cross-contamination in neonatal intensive care units. In other products, the infant beds may be rotated and tilted for medical procedures. Some of these Indian innovations were greatly appreciated even by the international manufacturers who recognized the Indian neonatal care equipment industry as a competitor and incorporated these features into their products.

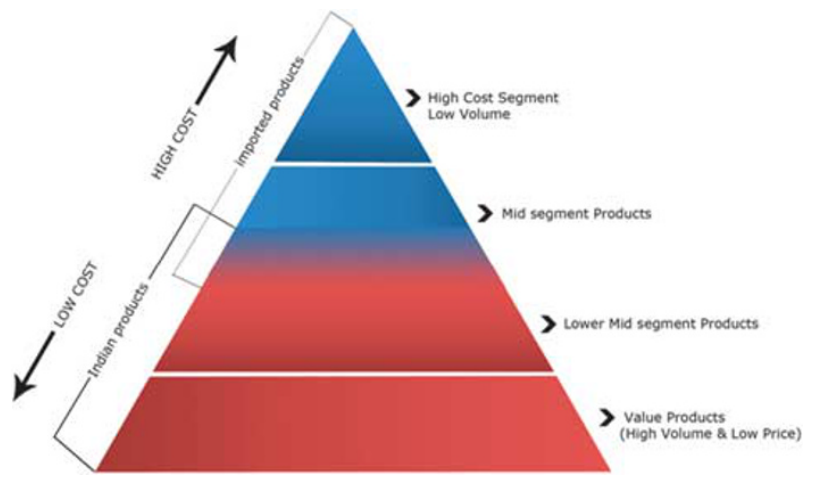

Figure 5. Neonatal care products sales pyramid.

Low cost is an important requirement in developing nations, and developing very good innovative products to meet this requirement is a strength of the Indian industry. Steadily, the made-inIndia resuscitation bags, phototherapy units, weighing scales and radiant warmers have succeeded in meeting the country's needs.

India is almost entirely self-reliant in terms of phototherapy units and infant warmers. And only Indian weighing scales and resuscitation equipment are used in Indian hospitals. But India still depends heavily on imported CPAP equipment, ventilators and incubators.

A number of Indian ideas are patentable-some of them were indeed patented. Indian industry has been focused on developing solutions for infant care. In the words of the leader of one company, 'Care for the patient, not for the patents' is the mantra. Even so, the neonatal care industry of the world is keenly interested in solutions from India. Going by present indications, Indian innovations will shape the solutions to come in the future. Indian industry can lead initiatives in meeting the Millennium Goals through products of international quality supplied at the right price.

Need for standards and regulation

India is seen as a potential global hub for affordable health technologies, including biomedical devices and equipment. We already have a vibrant industry that meets our local needs to a significant extent. In addition, a plethora of foreign companies have had a marketing base here for long. Others are keen on entering the research and development space, with or without partnerships with Indian companies, to generate products at affordable cost to meet the growing demand of users here and in other countries.

There is, however, no robust system to test the functioning and safety of the devices that would potentially be marketed in the country. Companies at times depend on individual researchers or professional organizations, who may have clinical expertise, but often no expertise in engineering or the key safety features.

There is a proliferation of irresponsible vendors who enter medical equipment business purely as an opportunity to make fast money without understanding the fundamental requirements of the equipment. Most users experience inadequate postinstallation service support from majority of the companies.

The prevailing scene is also a dampener for companies, Indian and foreign, that aim at developing and marketing products without compromising quality-because they often cannot match the cost advantage of the opportunistic sellers/producers of lowquality technology. In order to address these problems, following should be ensured: 
- Any new medical equipment/device that is marketed into India must be certified by a technical group comprising clinicians, engineers and scientists for performance and safety. Such a body, that may be named as a Technology Assessment Network for medical devices, could be a network of institutions spread across the country because it is unlikely that any or a few institutions in a city would have all the clinico-engineering expertise in all kinds of devices across specialties (that range from newborn care, eye care, heart surgery, endoscopy, joint implants, anesthesia, respiratory life support and so on).

- Only those devices that meet the established standards of performance and safety are marketed in the country by law. Such standards need to be developed by a body such as the Bureau of Indian standards. Anyone violating this should be liable for criminal charge. Such standards must also include post-installation service commitments by the marketing company to provide uninterrupted and efficient service no matter where in the country the equipment is installed.

- There must be a statutory regulatory authority that oversees and enforces the above and other norms. A draft Bill to create a Medical Devices Regulatory Authority has been developed by the Ministry of Science and Technology since 2006, but has not been taken up for enactment. There is an urgent need to take up this Bill and create the Authority and enforce the muchneeded regulation.

The future

The developments of the last two decades suggest that Indian products are likely to occupy a significant place in the global biomedical equipment market in the future. Neonatal care in India has changed greatly since the 1980s and 1990s. There is a widespread awareness about neonatal care equipment. Education and government initiatives have played a role, as has the spirit of technological innovation, which drove industry to work without seeking help from the government. An increasing number of manufacturers are moving to better quality. Recognizing this, international players (such as Stanford University) and foreign companies are looking toward India to develop products for the world market.

Notwithstanding the recent successes, Indian manufacturers and healthcare stakeholders have challenges to address. Respiratory problems are the next major neonatal affliction to be tackled. Indian incubators and CPAP devices and ventilators are still undergoing the transition to international quality and standards, whereas radiant warmers and phototherapy units have gained international (Conformité Européene and Food and Drugs Administration) approvals.

The initial problems faced by Indian companies have been overcome. India is in a position to cater to the health of the world's neonates through affordable technologies. Prime Minister Modi has given a clarion call for 'Make in India' to make India a manufacturing hub.

It is encouraging, in this situation, that a number of organizations and government agencies are now striking partnerships with Indian industry. The Department of Biotechnology has come out with a number of initiatives in which it encourages industry and innovators to participate. The Confederation of Indian Industry and the Federation of Indian Chambers of Commerce and Industry have submitted several proposals to the government to improve Indian neonatal healthcare and to develop Indian industry. Innovations are being actively supported at AIIMS and Indian Institute of Technology Delhi in association with Indian companies.

India is described today as being at the threshold of a neonatal survival revolution, with an abiding policy commitment to newborn health and a promising strategy for maternal and neonatal health, well supported by the commitment of the states. It is interesting to imagine whether the same situation would have prevailed, had the message of the AlIMS conference in 1990 been delivered just some years later and the foreign manufacturers had already entered India. And, it is also interesting to imagine what the story would have been if Indian industry had not responded to the message as it did.

\section{CONCLUSION}

This inspirational story of small-scale industry innovating affordable neonatal equipment has demonstrated the potential of Indian enterprise to meet the challenges of developing healthcare technologies for mass use. Without these efforts, India's newborn care, particularly in the facilities would have lagged behind considerably. The programs such as those implemented by the Department of Biotechnology (DBT/BIRAC) in support of industry and academia-driven innovations will go a long way in making India a hub of affordable healthcare technologies.

We need to encourage industry to develop high-quality, affordable equipment for newborn care through facilitation, resources and recognition, develop academia, industry and government partnerships for new and better neonatal equipment and ensure that only those devices that meet the established standards of performance and safety are marketed in the country by law. It is hoped that with the healthcare industry being a priority under the draft National Health Policy (2015), the future of neonatal equipment innovation, production and scale-up is brighter than ever. ${ }^{3}$

\section{CONFLICT OF INTEREST}

VSK owns equity and is the managing director of Phoenix Medical Systems, Chennai, India, manufacturers of medical equipment including neonatal care equipment. VSK has also received grant support from Wellcome Trust. KS has received consulting fees from Phoenix Medical Systems, Chennai, India, and has applied for a patent in this field. VKP declares no conflict of interest.

\section{ACKNOWLEDGEMENTS}

Support for this article was provided by Save the Children's Saving Newborn Lives program.

\section{REFERENCES}

1 Singh M, Paul VK, Deorari AK. Biomedical Equipment: Status and Perspectives. National Neonatology Forum: New Delhi, 1990.

2 Deorari AK, Paul VK. Neonatal Equipment: Everything You Would Like to Know, 4th edn., CBS Publishers and Distributors: New Delhi, 2012.

3 Ministry of Health and Family Welfare. Draft National Health Policy, New Delhi, 2015.

This work is licensed under a Creative Commons AttributionNonCommercial-NoDerivs 4.0 International License. The images or other third party material in this article are included in the article's Creative Commons license, unless indicated otherwise in the credit line; if the material is not included under the Creative Commons license, users will need to obtain permission from the license holder to reproduce the material. To view a copy of this license, visit http:// creativecommons.org/licenses/by-nc-nd/4.0/

(c) The Author(s) 2016 